\title{
OS MOVIMENTOS FEMINISTAS NA AMÉRICA-LATINA E AS PERSPECTIVAS PARA A EFETIVAÇÃO DOS DIREITOS SEXUAIS E REPRODUTIVOS DAS MULHERES BRASILEIRAS
}

\author{
FEMINIST MOVEMENTS IN LATIN AMERICA AND THE PERSPECTIVES FOR THE EFFECTIVENESS OF \\ SEXUAL AND REPRODUCTIVE RIGHTS BY BRAZILIAN WOMEN
}

\begin{abstract}
RESUMO
Este trabalho versa sobre a trajetória do feminismo como movimento catalisador de transformações econômicas, socioculturais e políticas voltadas à melhoria das condições de vida das mulheres e superação das relações de gênero. Analisar-se-á o panorama latino-americano referente à ampliação e asseguração dos direitos sexuais e reprodutivos das mulheres, objetivando examinar as perspectivas brasileiras quanto à materialização da autonomia reprodutiva de sua população feminina e as limitações político-legislativas e socioculturais do país que impedem a efetivação desses direitos. Vale-se do método de abordagem dedutivo e dos métodos de procedimento histórico e monográfico, sendo a técnica de pesquisa empregada a documentação indireta. Deste estudo, compreendeu-se que a invisibilidade das mulheres brasileiras é sedimentada pela ausência de reconhecimento da realidade social das mulheres e da significativa manifestação de casos de violência de gênero, sendo a inclusão da perspectiva de gênero nas leis e políticas públicas uma forma de assegurar a emancipação feminina.
\end{abstract}

Palavras-chave: Movimentos Feministas. América Latina. Direitos Sexuais. Direitos Reprodutivos. Mulheres Brasileiras.

\begin{abstract}
This work deals with the trajectory of feminism as a catalyst movement for economic, socio-cultural and political transformations aimed at improving women's living conditions and overcoming gender relations. The Latin American panorama regarding the expansion and assurance of women's sexual and reproductive rights will be analyzed, aiming to examine the Brazilian perspectives regarding the materialization of the reproductive autonomy of its female population and the country's politicallegislative and socio-cultural limitations that hinder the enforcement of these rights. It uses the deductive approach method and the historical and monographic procedure methods, with the research technique being the indirect documentation. From this study, it was understood that the invisibility of Brazilian women is consolidated by the lack of recognition of the social reality of women and the significant manifestation of
\end{abstract}

Bruna B. Vedana

Graduada em Direito pela Faculdade Meridional - IMED-PF. Email: vedana.bruna@gmail.com

Tássia A. Gervasoni

Doutora em Direito pela Universidade do Vale do Rio dos Sinos. Email: tassiagervasoni@gmail.com 
cases of gender violence, with the inclusion of gender perspective in laws and public policies as a way of ensuring female emancipation.

Keywords: Feminist Movements. Latin America. Sexual Rights. Reproductive Rights. Brazilian Women.

\section{Introdução}

O discurso acerca dos direitos da mulher é marcado por controvérsias sociais e culturais que se evidenciam, ainda hoje, no modo em que as mulheres são contempladas na legislação.

Diante de um contexto marcado por condutas e comportamentos machistas, bem como relações de poder e dominação instituídas entre os sexos, ganhou destaque a inserção das mulheres em movimentos sociais reivindicatórios, demandando igualdade nas relações e superação de padrões socioculturais opressivos. A participação feminina nas lutas em prol da libertação e emancipação da mulher, aliada ao ativismo pela garantia e materialização de seus direitos, originou o movimento feminista.

Entretanto, apesar de a mobilização feminista ter contribuído para o progresso das relações de igualdade nos demais países latino-americanos, o Brasil ainda oferece às suas cidadãs condições precárias no que se refere à garantia de seus direitos fundamentais, especialmente os sexuais e reprodutivos.

Frente a tais premissas, este estudo busca analisar as violências sofridas pelas mulheres brasileiras na luta por seus direitos sexuais e reprodutivos em razão de seu gênero. Além disso, face a tais situações, é indispensável examinar o papel do movimento feminista na desestruturação das bases culturalmente discriminatórias da sociedade brasileira, inclusive mediante o estímulo do reconhecimento da perspectiva de gênero como um instrumento de garantia dos direitos humanos das mulheres.

Para tanto, realiza-se uma breve análise sobre o percurso histórico do movimento feminista e suas reivindicações, especialmente em relação à superação das discriminações de gênero, expondo-se as renovações constitucionais e infraconstitucionais ocorridas nos países sul-americanos, sobretudo no Brasil, Chile, Uruguai e Argentina voltadas à asseguração dos direitos reprodutivos das mulheres, bem como as políticas públicas implementadas, com o fim de promover a tutela reprodutiva das mulheres latino-americanas. Por fim, realiza-se uma análise sobre a ausência de reconhecimento das raízes opressoras da sociedade e das desigualdades de gênero ainda presentes no contexto social, como uma circunstância para o atraso legislativo e governamental do Brasil quanto à materialização dos direitos reprodutivos da população feminina.

O desenvolvimento do trabalho dá-se com a utilização do método deabordagem dedutivo e dos métodos de procedimento histórico e monográfico, baseando-se nas 
reivindicações históricas do movimento feminista e sua influência nas transformações sociais que visam à contemplação dos direitos reprodutivos das mulheres. Para tanto, em termos de técnica de pesquisa, será empregada a documentação indireta, realizando-se uma pesquisa bibliográfica sobre a problemática.

\section{As questões degêneroe agarantiados direitos sexuais e reprodutivos das mulheres latino-americanas}

O movimento feminista fundamenta-se, entre outros pontos, no ideal de libertação da mulher, atuando de forma progressiva para a asseguração dos direitos da população feminina. Desde sua origem, o feminismo expôs o retrato problemático da sociedade mundial, o qual prestigia a experiência masculina de domínio e menospreza o histórico de dominação enfrentado pelas mulheres, fato que dificulta a percepção das mulheres como seres de direitos.

Nessa perspectiva, objetiva o movimento o rompimento com a configuração patriarcal da sociedade, baseada em construções sociais discriminatórias e opressivas, fornecendo às mulheres força política e social para intervirem como agentes catalisadores de transformações sociais. Nesse sentido, concebe-se o feminismo como um "movimento político [que] questiona as relações de poder, a opressão e a exploração de grupos de pessoas sobre as outras. Contrapõe-se radicalmente ao poder patriarcal. Propõe uma transformação social, econômica, política e ideológica da sociedade" (Teles, 1993: 10).

Para tanto, a produção de um conhecimento científico e sociológico acerca da dominação masculina, possibilitada pelo crescimento dos debates feministas, foi essencial para fornecer as bases críticas necessárias para o questionamento das relações de gênero e da cultura patriarcal - construções sociais que legitimam a dominação dos homens sobre as mulheres e, portanto, amparam casos de violência de gênero.

A compreensão do termo "gênero" está diretamente ligada ao crescimento do movimento feminista contemporâneo, sendo popularizado com a publicação, em 1986, do artigo "Gênero: uma categoria útil de análise", onde se afirma que gênero:

[...] tem duas partes e diversas subpartes. Elas são ligadas entre si, mas deveriam ser distinguidas na análise. O núcleo essencial da definição repousa sobre a relação fundamental entre duas proposições: (1) gênero é um elemento constitutivo de relações sociais baseado nas diferenças percebidas entre os sexos, e (2) o gênero é uma forma primeira de significar as relações de poder (Scott, 1995: 86).

Em seu estudo, a escritora critica a desconsideração da conjuntura histórica no processo de dominação masculina, pois a configuração da sociedade decorre de 
seu desenvolvimento cultural e político. Afirma, assim, que as relações de gênero e de poder dos homens sobre as mulheres são construções sociais simbólicas, baseadas na oposição entre características apontadas como femininas e masculinas, as quais foram historicamente utilizadas para a legitimação da lógica de dominação masculina. Destaca, portanto, a necessidade de uma visão mais ampla acerca do histórico de desigualdades enfrentado pelas mulheres para a sua efetiva emancipação e, consequentemente, para a garantia de seus direitos (Scott, 1995).

Diante dessa filosofia, questões relacionadas aos direitos reprodutivos, à violência doméstica e à equidade salarial, bem como a própria característica patriarcal da sociedade, passaram a ser analisados por um viés crítico e questionador. Ao levar seu foco à problemática da hierarquia entre os sexos, passando a observar suas consequências práticas para a vida da mulher, observa-se que os estudos de gênero proporcionaram uma maior visibilidade aos direitos das mulheres.

No cenário latino-americano, destaca-se que a superação dos períodos ditatoriais foi imprescindível para a garantia dos direitos da população feminina. Isso porque, apesar das particularidades de cada sistema político, os governos autoritários que se estabeleceram na América Latina, caracterizaram-se predominantemente pela violência, tortura, cerceamento do direito à liberdade de expressão e por, sistematicamente, violarem as liberdades básicas dos cidadãos.

Necessário enfatizar, outrossim, a misoginia presente durante o período repressivo. Na ditadura, a questão feminina era vista com um olhar conservador, patriarcal, tendo elas um papel de donas de casa, promotoras de valores familiares tradicionais. Ademais, eram constantes as torturas e violências sexuais, as quais tinham como escopo sua humilhação e desestruturação, mediante a apropriação de seus corpos, consistindo, principalmente, em casos de estupro; utilização de choques elétricos nos órgãos genitais; inserção de animais vivos, como baratas e ratos, nos corpos das torturadas; nudez forçada; ameaças de violação; humilhações de cunho sexual e abortamentos forçados (Brasil, 2014: 399-435).

A ascensão de políticas de proteção dos direitos humanos em âmbito internacional, ocorrida principalmente nas sociedades europeias e estadunidenses a partir dos anos 1970, destacou a incompatibilidade do autoritarismo com a promoção dos interesses e direitos da sociedade. Igualmente, o aumento excessivo das dívidas externas e o crescimento acelerado da inflação e das crises econômicas, consectários da política de desenvolvimentismo adotada pelos militares, bem como a intensificação das mobilizações sociais contra o governo, contribuíram para a derrocada dos regimes militares na América Latina (Gomes \& Delgado, 2016: 251-252).

Tal processo facilitou, também, o fortalecimento do cenário feminista e a publicização dessas mobilizações e lutas sociais. Não tardou, do mesmo modo, a formação de entidades não governamentais em apoio à consolidação do movimento feminista, as quais foram amplamente influenciadas pelas organizações internacionais, tendo como inicial e principal foco o auxílio de mulheres vítimas de violência doméstica e estupro. 
O período de transição democrática ocorrido nos países latino-americanos, com a consequente renovação das cartas constitucionais, foi primordial para a edificação de um Estado democrático e, inclusive, mais equânime, mediante a internalização do sistema internacional de proteção dos direitos humanos às legislações nacionais, traduzindo-se no reconhecimento e formalização das reivindicações concretas da população.

Nessa perspectiva, Piovesan (2018: 61) afirma que a promoção dos direitos humanos somente é compatível com o regime democrático. Isso acontece porque a democracia assegura o direito mais básico de todos, sendo, portanto, indispensável ao processo de ampliação da cidadania: o direito de ter direitos. Observa-se, assim, que a democracia possibilita um maior gozo das liberdades individuais e coletivas, o que impulsiona o processo de construção e reconstrução, típico dos direitos humanos.

Dessa forma, constata-se que, durante os períodos ditatoriais na América Latina, o ideal dos direitos humanos não tinha oportunidade de expansão, já que as políticas de opressão do governo, pavimentadas pela violência estatal, frustravam a abordagem de tal assunto nas pautas sociais. Logo, as mobilizações populares, aliadas às ações internacionais, foram essenciais para a transformação do contexto político e cultural latino-americano, uma vez que promoveram um maior engajamento nas experiências de luta pela igualdade e resistência à cultura da dominação.

Nesse sentido, a transição democrática da América Latina, ocorrida a partir do final da década de 1970, por meio de articulações e mobilizações sociais, contribuiu, portanto, para o reconhecimento dos direitos fundamentais mediante a inserção de novos direitos nas cartas constitucionais. Dessa forma, a participação das mulheres na renovação dos textos constitucionais e sua interferência nas políticas de Estado foram essenciais para a consolidação e ampliação dos seus direitos e, consequentemente, para a criação de um quadro legislativo mais favorável à população feminina.

No contexto brasileiro, o Conselho Nacional dos Direitos da Mulher (CNDM) foi fundamental para a presença feminina, tanto no entorno quanto no interior da Assembleia Constituinte, tendo impulsionado, por meio da campanha Mulher e Constituinte, a eleição de 26 deputadas para contribuírem na formulação da nova Constituição'. Formou-se, então, uma aliança entre as parlamentares e o movimento feminista, denominada "Lobby do Batom", a qual oportunizou a interlocução das mulheres com o Estado, viabilizando a defesa dos seus direitos. (Monteiro, 2018).

Com enfoque na campanha, "Constituinte pra valer tem que ter palavra de mulher", foi entregue ao presidente da Assembleia Nacional Constituinte pelo CNDM, em 1987, a "Carta das Mulheres Brasileiras aos Constituintes", a qual capitulava as demandas da articulação feminina para o novo texto constitucional, restando aprovadas $80 \%$ dessas reivindicações, as quais foram incorporadas ao novo texto constitucional (Monteiro, 2018).

Uma das conquistas mais substanciais foi a da igualdade entre direitos e obrigações de homens e mulheres, prevista no art. 5oㅗ I, da Constituição Federal,

1 Anteriormente, apenas uma mulher tinha sido eleita deputada constituinte: Carlota Pereira de Queiroz, em 1934. (Monteiro, 2018). 
sendo a proibição de discriminação em razão do sexo, inclusive, considerada um dos objetivos fundamentais da República Brasileira, fator que propiciou a ampliação dos direitos das mulheres brasileiras. (Silva \& Wright, 2015: 179-180). O princípio da igualdade jurídica entre homens e mulheres consagrou-se, também, nos textos constitucionais de Argentina, Chile e Uruguai, sendo significativo para a publicização das discriminações existentes na sociedade latino-americana e para assegurar os direitos da população feminina.

Assim, os instrumentos internacionais de proteção dos direitos humanos impulsionaram as transformações jurídico-normativas internas constitucionais e infraconstitucionais nos países em estudo, evidenciando-se nas inovações voltadas aos direitos políticos, mediante o sufrágio universal e a reserva de cotas para as candidaturas femininas; aos direitos trabalhistas, por meio da proibição de práticas discriminatórias e do estabelecimento do direito à igualdade salarial; e ao direito à vida, com a articulação de leis e programas destinados ao combate da violência doméstica e familiar e do feminicídio.

Todavia, embora as mulheres tenham se mobilizado, historicamente, pela ampliação de seus direitos e pelo fim das violências, o que contribuiu para a construção formal e legislativa do novo sistema político em vigor na América Latina e, portanto, para a garantia dos direitos acima descritos, observa-se que a condição feminina não se encontra devida e integralmente amparada, uma vez que o processo de redemocratização não significou a imediata contemplação dos seus direitos sexuais e reprodutivos.

Com efeito, no Brasil, em que pese a tutela da instituição da família e a disposição acerca da liberdade no planejamento familiar, no art. 226, §7ํㅡㄹ da Constituição Federal, as demandas referentes a tais direitos, como a livre expressão sexual e o aborto, enfrentaram a resistência dos demais constituintes, fazendo com que o movimento feminista brasileiro não atingisse seus objetivos nesse ponto (Monteiro, 2018).

Nesse sentido, a Constituição Federal, de 1988, dispõe acerca da inviolabilidade do direito à vida desde a sua concepção, sendo o Código Penal responsável pela previsão de penas privativas de liberdade àqueles que realizam práticas abortivas, com ou sem consentimento da gestante. Até 2012, afastava-se o caráter ilícito do crime apenas quando a gravidez resultasse de estupro ou em caso de grave risco de morte para a gestante (Brasil, 1940). Naquele ano, porém, por meio do julgamento da Arguição de Descumprimento de Preceito Fundamental (ADPF) no 54, o Supremo Tribunal Federal possibilitou nova interpretação das normas penais, ao decidir que a interrupção de gravidez de feto anencéfalo, ressalvado o direito subjetivo da gestante de querer ou não a antecipação do parto, não configura o crime de aborto, representando, portanto, uma hipótese de parto antecipado, com fim terapêutico (Brasil, 2012).

Já as Constituições de Chile, Uruguai e Argentina preveem a proteção da instituição familiar, porém sequer reportam-se ao conceito de planejamento familiar 
ou de ações preventivas e educativas sobre a sexualidade ${ }^{2}$. Ainda, assim como a brasileira, as cartas constitucionais chilena e argentina vedaram a realização de técnicas abortivas, havendo a tipificação criminal do aborto em seus respectivos códigos repressivos.

No Chile, até 2017, o crime de aborto não previa nenhuma causa excludente de ilicitude, sendo este punido, portanto, em todas as circunstâncias. Em 21 de agosto de 2017, diante de pressão social e recomendação de órgãos internacionais, o Tribunal Constitucional do Chile aprovou a descriminalização do aborto em casos de risco à vida da gestante, estupro e inviabilidade fetal (Montes, 2017).

As novas demandas sociais, organizadas em campanhas pelo aborto legal, seguro e gratuito, propiciaram, na Argentina, um debate legislativo acerca da adequação da lei ao crescente processo de concretização dos direitos das mulheres, o que conduziu à aprovação, pela Câmara dos Deputados, em 2018, de um projeto de lei pela legalização da interrupção da gravidez até a $14^{\underline{a}}$ semana de gestação. $\mathrm{O}$ conservadorismo do Senado, porém, prevaleceu diante dos direitos das mulheres, sendo o projeto rejeitado pela Casa Legislativa, mantendo-se o texto do Código Penal argentino, de 1921, que permite a realização de práticas abortivas apenas em casos de estupro ou de risco de vida à gestante (Centenera \& Molina, 2018).

O Uruguai, por sua vez, destaca-se como uma exceção no cenário latinoamericano: é o único país em que o aborto é legalizado em circunstâncias mais amplas. Modificando o Código Penal, a lei no 18.987, de 2012, possibilita a realização da interrupção voluntária da gravidez nas primeiras doze semanas de gestação, sendo, inclusive, fornecido apoio assistencial, médico e psicológico àquelas que desejarem abortar (Uruguai, 2012).

Dessa forma, observa-se que a legislação latino-americana, em regra, desconsidera os direitos reprodutivos e sexuais da população feminina e pouco avança para o seu reconhecimento e materialização. Contudo, verifica-se que, em contraponto aos demais países latino-americanos, o sistema político-legislativo brasileiro apresenta maiores dificuldades na efetiva garantia desses direitos, uma vez que as políticas públicas, implementadas pelo Estado, demonstram-se ineficazes em promover a efetiva autonomia reprodutiva das mulheres.

Nesse contexto, após a redemocratização da América Latina, as questões relacionadas a programas de saúde voltados à mulher firmaram-se como um tema prioritário nas reivindicações feministas.

Em atenção às modificações e demandas sociais, o Ministério da Saúde do Brasil elaborou, em 1984, o Programa de Assistência Integral à Saúde da Mulher (PAISM). Com ênfase na questão de saúde sexual e reprodutiva e na população materno-infantil, o documento salienta a importância do oferecimento de uma tutela integral à saúde da mulher, desde a adoção de medidas educativas quanto à

2 Enquanto no Brasil a previsão acerca do planejamento familiar é constitucional e infraconstitucional, nos termos da Lei no 9.263/96, na Argentina, no Uruguai e no Chile, as únicas disposições são infraconstitucionais, conforme lei oㅡ 25.673, de 2002, lei ㄲo 18.426, de 2008, e lei ㄲo 20 . 418, de 2010, respectivamente (Cepal, 2012: 28). 
concepção e contracepção, investimento na capacitação dos profissionais envolvidos nas práticas de controle pré-natal e parto, até a incorporação de temas relacionados a câncer de colo de útero e de mama. Ainda, intentando suprir as necessidades das mulheres, o governo brasileiro criou, em 2004, a Política Nacional de Atenção Integral à Saúde da Mulher (PNAISM), a qual, da mesma forma que o Programa anterior, tinha como objetivo a articulação e melhor execução de políticas públicas de saúde (Pitanguy, 2003: 30-33).

O movimento feminista também se fez presente, por meio do Conselho Nacional dos Direitos da Mulher, em diversas comissões e campanhas realizadas para a efetivação das políticas acima referidas, e para a materialização do direito das mulheres à saúde. Nesse sentido, pode-se destacar sua articulação junto ao Ministério da Saúde, na Comissão de Direitos Reprodutivos e nas Campanhas Nacionais de Combate à Mortalidade Materna e de Prevenção do Câncer Mamário e CérvicoUterino, elaborando, inclusive, palestras e seminários destinados à população feminina sobre seus direitos (Pitanguy, 2003: 35-37).

Contudo, de acordo com o relatório do Programa das Nações Unidas para o Desenvolvimento (PNUD, 2018), o Brasil apresenta elevados índices de mortalidade materna: a cada 100.000 mulheres, 44 morrem em decorrência de complicações na gestação, parto ou pós-parto. Ainda, é grande a incidência da gravidez na adolescência: a cada 1.000 partos, 62 deles são realizados em mulheres de 15 a 19 anos.

Da mesma forma, os dados sobre violência obstétrica no Brasil são alarmantes. Caracterizada pelo emprego de atos física ou psicologicamente violentos nos períodos da gestação, parto e pós-parto, assim como pelo uso excessivo de medicamentos e procedimentos que desumanizam as mulheres, a violência obstétrica pode ser exemplificada pela restrição do direito a acompanhantes e ao alívio da dor, por xingamentos, piadas desrespeitosas e constrangimentos e pela realização de cirurgias desnecessárias que impactam na saúde da mulher e retiram sua autonomia sobre seus corpos (Venturi \& Godinho, 2013).

Conforme os dados de uma pesquisa estruturada em 2014, cerca de 70\% das brasileiras deseja um parto normal no início da gestação; entretanto, 57\% dos partos no país são realizados por meio de cesarianas, taxa muito superior à indicada pela Organização Mundial da Saúde, de 15\%, em razão das constantes complicações médicas acarretadas pelo procedimento cirúrgico (Fundação Oswaldo Cruz, 2014). Da mesma forma, estatística realizada em 2010 demonstra que uma a cada quatro mulheres brasileiras foi maltratada durante o trabalho de parto (Venturi \& Godinho, 2013).

Ademais, é necessário atentar que, não obstante a existência das referidas pesquisas, os dados acerca da violência obstétrica no país ainda são frágeis, uma vez que muitas mulheres não denunciam as violações sofridas ou normalizam as experiências enfrentadas como se inerentes ao contexto da gestação e do parto. A fim de prevenir e punir tais abusos, observa-se que o governo argentino, ao legislar sobre a coibição da violência doméstica e familiar, na lei no 26.485 de 2009, incluiu a 
temática da violência obstétrica, evidenciando-a como uma modalidade de violência de gênero (Souza, 2013).

Contudo, o Brasil não avançou quanto à questão, não havendo, portanto, qualquer tutela legislativa das mulheres que enfrentam tais violações. Além disso, o progresso também não pode ser identificado no âmbito sociocultural, mediante a transformação dos costumes e práticas médicas: em maio de 2019, o Ministério da Saúde emitiu um despacho defendendo a abolição do termo "violência obstétrica", pois estaria vinculado à intencionalidade dos profissionais em causar danos às gestantes, afirmando que este "tem conotação inadequada, não agrega valor e prejudica a busca do cuidado humanizado no continuum gestação-parto-puerpério” (Brasil, 2019)³. Entretanto, considerando que o tema é frágil e insuficientemente discutido perante a dimensão dos casos de violência obstétrica no país, uma censura institucional do termo apenas dificulta o reconhecimento dessa modalidade de abuso e dos direitos das mulheres a um sistema de saúde humanizado, que respeite a autonomia das gestantes sobre seu corpo no contexto do parto.

Ainda neste contexto, cabe destacar a importância do planejamento familiar, o qual amplia o acesso da população a informações, métodos de contracepção e meios de prevenção de infecções sexualmente transmissíveis, oportunizando a livre e consciente escolha entre ter ou não ter filhos. No Brasil, tais ações educativas foram implementadas pela Política Nacional de Planejamento Familiar, de 2007, cujo foco compreende o fornecimento gratuito de métodos contraceptivos para homens e mulheres. No cenário latino-americano, destaca-se a Política de Planificación Familiar do Chile, a qual, desde 1964, atua em favor da ampliação do acesso a informações e da popularização de mecanismos de regulação da fertilidade. Cabe destacar, nesse sentido, a efetividade das ações relacionadas aos cuidados básicos com as gestantes, refletindo-se no baixo nível de mortalidade materna: a cada 100.0oo nascimentos, apenas 22 mulheres morrem em decorrência de complicações durante a gravidez, o parto ou o puerpério. No Brasil, em comparação, essa taxa é de 44 mulheres (FUNDO DAS NAÇÕES UNIDAS PARA A INFÂNCIA, 2018: 41-62).

Diante de tais dados, observa-se que, enquanto Argentina, Chile e Uruguai avançam para a incorporação das demandas de suas cidadãs no ordenamento jurídico nacional e para a implementação de políticas públicas que efetivem seus direitos, o Brasil ainda enfrenta dificuldades na materialização dos direitos reprodutivos das mulheres.

O panorama que se tem construído no país, embasado na desconsideração dos direitos reprodutivos das mulheres, encontra-se fortemente limitado pela cultura patriarcal e pelas relações de poder, que legitimam a dominação do homem sobre a mulher e, consequentemente, obstam a superação das de gênero.

3 Em junho de 2019, após recomendação do Ministério Público Federal, o Ministério da Saúde reconheceu a legitimidade do uso do termo, porém afirmou que continuará a não utilizar a expressão (Cancian, 2019). 


\section{O reflexo das relações de gênero no atraso político-legislativo brasileiro}

A difusão do movimento e a afirmação da agenda feminista contribuíram para que as especificidades das vivências femininas passassem a ser incorporadas nas questões legislativas e governamentais. Todavia, a despeito da criação de leis mais inclusivas e da implementação de políticas públicas destinadas à melhoria da realidade social das mulheres, ainda é manifesta, no atual contexto brasileiro, a existência de um quadro de negligência em relação aos direitos reprodutivos das mulheres.

Com efeito, pode-se observar pelos dados acima apresentados que, em contraponto aos demais países latino-americanos estudados, as brasileiras possuem uma tutela menos efetiva dos seus direitos reprodutivos. Assim, apesar de as conquistas obtidas pelo movimento feminista, especialmente após a redemocratização do país, terem oportunizado a criação de um quadro mais favorável à garantia de seus direitos, a consolidação de sua autonomia reprodutiva ainda esbarra na presença do sexismo nas relações sociais atuais e na permanência de uma dinâmica de poder e controle de gênero refletindo na inexistência de uma efetiva emancipação sexual das mulheres.

Um dos principais passos históricos dado em direção ao empoderamento reprodutivo das mulheres constitui-se no controle de natalidade. Para tanto, as mobilizações feministas foram imprescindíveis para o encorajamento da sexualidade feminina e para a desvinculação da maternidade como sendo o único papel da mulher.

Nessa perspectiva, a implementação do Programa de Assistência Integral à Saúde da Mulher (PAISM) no Brasil, em 1984, proporcionou a redefinição do significado do corpo da mulher, pois foi dado um enfoque mais amplo às políticas de saúde do segmento feminino, sendo concebidas ações de proteção integral, além da simples análise de sua saúde reprodutiva. Todavia, apesar de as políticas de controle de natalidade figurar como reivindicações feministas nesse ponto, as ações sobre fertilidade adotadas no país ainda possuem um aspecto patriarcal.

De acordo com Reis (2010, p. 80-82), a questão do controle reprodutivo foi introduzida no contexto latino-americano não como uma forma de prover uma autodeterminação às mulheres, mas como um meio de controle do crescimento populacional, especialmente da parcela negra e pobre, podendo ser destacados, inclusive, projetos de imposição e coerção do uso de métodos contraceptivos nas mulheres brasileiras ${ }^{4}$.

Atualmente, também são apontados diversos problemas nas ações de planejamento familiar brasileiras. Nesse sentido, em que pese a disponibilidade de diversos métodos de contracepção, a desinformação da população feminina e a ausência de orientação médica prejudicam a compreensão acerca das corretas

4 Destaca-se, nesse ponto, a instauração de uma Comissão Parlamentar de Inquérito (CPI), em 1992, para investigar denúncias de esterilização em massa de mulheres, notadamente negras, no Brasil. 
formas de utilização e os eventuais riscos advindos do uso de tais métodos, fazendo com que as mulheres não possam realizar uma escolha informada sobre sua saúde e, portanto, não tenham sua autonomia reprodutiva assegurada.

Há de se ressaltar, outrossim, que alguns desses métodos contraceptivos, como cirurgias e implantes, são invasivos, e outros, como pílulas anticoncepcionais, apresentam diversos riscos colaterais indesejados, como trombose e embolia pulmonar, hipertensão, doenças cardíacas, diabetes e depressão (Reis, 2010: 82). Enquanto isso, as pesquisas voltadas à criação de um "anticoncepcional” masculino foram suspensas pela apresentação de efeitos colaterais semelhantes aos dos femininos, os quais, segundo os órgãos fiscalizadores, ofereceriam graves riscos à saúde dos homens (Vaiano, 2016).

Ainda nesse ponto, em atenção à Lei do Planejamento Familiar, verifica-se que, para o procedimento de esterilização voluntária das mulheres, consistente na realização de uma laqueadura (ligação das trompas uterinas) ou de uma histerectomia (retirada do útero), por exemplo, é necessária a autorização do cônjuge, fato que retira da mulher seu direito de autodeterminação (Brasil, 1996). Outrossim, cabe salientar que, embora haja o preenchimento dos requisitos, são frequentes os relatos de recusa na realização do procedimento, normalmente por motivos religiosos 5 .

No entanto, uma das mais visíveis formas de dominação patriarcal existente hoje no Brasil é a criminalização da interrupção voluntária da gravidez. Isso porque, mesmo havendo a realização de diversas campanhas a favor da legalização do aborto, a discussão sobre o direito de escolha ainda é limitada, partindo-se do princípio que a subjugação do corpo da mulher ao controle masculino e a vinculação destas ao papel da maternidade são preceitos centrais da cultura patriarcal.

É nesse sentido que a luta das mulheres pelos seus direitos se enquadra. Quando as feministas lutam pela legalização do aborto, não estão apenas colocando o aborto em questão, mas um sistema que domina e explora mulheres, que instrumentaliza a sua capacidade biológica e as reduz ao único destino da maternidade como sua função social (Carloto \& Damião, 2018: $311)$.

A ilegalidade do aborto, porém, não impede a sua prática: diversas mulheres, querendo interromper sua gravidez, valem-se de abortos clandestinos, inseguros e perigosos, que muitas vezes geram riscos a sua vida. Além disso, enquanto a parcela mais rica da população tem acesso às clínicas de abortamento ilegais, menos precárias e com mais higiene, a parcela jovem, negra e de classe baixa é a que mais sofre com a proibição do aborto, pois, por insuficiência econômica, não possui condições de realizar o procedimento de modo seguro. A negação da autonomia das mulheres sobre seus próprios corpos, retirando-lhes a opção da maternidade voluntária, é

5 Nesse sentido, vide: "com 55\% de gestações não planejadas, Brasil falha na oferta de contracepção eficaz" (Passarinho \& Franco, 2018). 
também caso de saúde pública: segundo dados do Ministério da Saúde, mais de 250 mil mulheres são hospitalizadas, anualmente, em razão de complicações oriundas de abortos clandestinos. Ainda, no ano de 2016, a prática de abortos inseguros causou a morte de 203 mulheres, correspondendo a uma morte a cada dois dias (Carloto \& Damião, 2018: 310).

No Chile e na Argentina, a prática do aborto também é criminalizada, tendo as mulheres um direito similar ao das brasileiras: pode-se apenas recorrer ao procedimento em casos de risco à vida da gestante, estupro ou má-formação do feto. Na Argentina, pode-se observar uma efervescência das demandas sociais pela materialização dos direitos reprodutivos das mulheres, especialmente por meio da Onda Verde, que transformou em reivindicação social a pauta da ampliação do direito ao aborto. Considerando que, no país, cerca de uma mulher morre por semana em razão de abortos clandestinos, o movimento alinhou-se em torno do lema "educación sexual para decidir, anticonceptivos para no abortar, aborto legal para no morir", angariando mais de 100.000 assinaturas a favor de sua descriminalização (Brieger, 2018).

Observa-se, nesse sentido, que o aborto foi tratado, pelo movimento argentino, como uma questão de saúde pública, destacando-se que sua clandestinidade reproduz o contexto latino-americano de desigualdade socioeconômica e que a falta de acesso às informações sobre educação sexual e métodos contraceptivos limita o direito das mulheres à autodeterminação.

A mobilização pela descriminalização da prática repercutiu, também, nos demais países latino-americanos, como no Chile, onde foram organizadas marchas populares em favor do aborto livre, legal, seguro e gratuito, bem como apresentado ao poder legislativo nacional um projeto de lei que possibilita a interrupção voluntária da gravidez até a 14 ${ }^{\underline{a}}$ semana de gestação (Chile, 2018).

De outra banda, o Uruguai é o único país em estudo que possibilita o aborto até a 12 $2^{-a}$ semana de gestação, conforme legislação implementada em 2012. De acordo com os dados divulgados pelo Ministério da Saúde Pública do país, após a legalização da prática, houve um crescimento no número de mulheres que desistiram de interromper a gravidez, bem como uma diminuição na taxa de mortalidade feminina em razão do aborto (Briozzo et al., 2016). Tais estimativas destacam os benefícios da descriminalização do aborto: além de garantir o direito das mulheres ao planejamento familiar, assegura-lhes uma rede de proteção, física e psicológica, que promove a reflexão sobre a prática e assevera tratamento médico especializado àquelas que decidirem prosseguir com o procedimento.

No Brasil, apesar de haver a existência de mobilizações sociais voltadas à legalização do aborto, os poderes legislativo e judiciário caminham para o lado oposto, uma vez que apenas avançam em propostas que tornam a interrupção da gravidez mais rígida. O julgamento da Arguição de Descumprimento de Preceito Fundamental no 442, que dispõe sobre a descriminalização do aborto até a $12^{\text {a }}$ semana de gestação, permanece desde 2018 no Supremo Tribunal Federal, sem a designação de data para votação. Além disso, verifica-se a criação de projetos de lei que dificultam 
a realização de procedimentos abortivos, ou, até mesmo criminalizam o aborto em todas as suas formas (Passarinho, 2018).

Igualmente, há de se ressaltar que, no contexto atual, um dos principais desafios à construção de leis e políticas para o combate da desigualdade de gênero e, consequentemente, para a ampliação dos direitos das mulheres, é a dificuldade de se estabelecer de discussões amplas e profundas acerca das relações de gênero e do caráter patriarcal da cultura brasileira.

Com efeito, as alterações na estrutura social, obtidas pelo movimento feminista durante sua história, estão diretamente vinculadas ao reconhecimento do quadro de desigualdade de gênero existente e do papel da mulher como sujeito ativo nas iniciativas transformadoras.

Nesse sentido, observa-se que o eixo do movimento feminista, numa análise histórica, consistiu no reconhecimento das mulheres como sujeitos de direitos e na incorporação de suas reivindicações ao sistema político-legislativo, com o escopo de eliminar as discriminações. Assim, especialmente em relação aos direitos sexuais e reprodutivos, destaca-se que a compreensão acerca de tais questões faz-se necessária para a superação das relações de gênero e das construções sociais que limitam a autonomia das mulheres, bem como para que se desconstrua a legitimação da lógica de dominação masculina sobre o corpo feminino.

Para tanto, diversos documentos internacionais estabelecem especificamente a adoção de medidas educativas destinadas ao combate das disparidades de gênero como uma ferramenta de empoderamento feminino e um mecanismo de superação das desigualdades.

Nessa perspectiva, os estudos de gênero foram inseridos nos currículos escolares, no contexto latino-americano, desde o final dos regimes militares, momento em que foram concebidas políticas de reflexão sobre as violências de gênero e as desigualdades jurídicas entre homens e mulheres. Da análise dos avanços legislativos de Argentina, Uruguai e Chile, pode-se observar que a manutenção de tal pensamento atuou como forma de asseguração dos direitos das mulheres, uma vez que suas leis e políticas públicas priorizam a compreensão do quadro de desigualdade social existente.

De modo efetivo, verifica-se que, no Uruguai, as políticas públicas implementadas assimilam a diversidade das violações sofridas pelas mulheres, por meio da adoção de medidas específicas e adaptáveis às diferenças geográficas, sociais e culturais existentes no país, potencializando-se, assim, sua eficácia.

Destarte, na Argentina, tanto a Ley de Protección Integral a las Mujeres, que coíbe todas as formas de violência contra as mulheres, quanto as ações articuladas para sua implementação, dispõem sobre a necessidade da identificação de eventuais padrões socioculturais que fortalecem a reprodução da violência de gênero, como também determinam a inclusão da perspectiva de gênero no âmbito educacional. Nesse ponto, destaca-se que os estudos de gênero, chamados de Prácticas Pedagógicas en Educación Sexual Integral pela legislação do país, foram efetivamente inseridos nos currículos acadêmicos, especialmente do ensino médio, contribuindo para o 
aprofundamento e a desnaturalização destes temas desde a adolescência. Além disso, desde novembro de $\mathbf{2 0 1 6}$, foram distribuídas mais de 40.000 cartilhas didáticas sobre a violência de gênero nas escolas de ensino fundamental do país (Unicef, 2018: 7375).

Da mesma forma, o Chile também estabeleceu mecanismos para a inclusão da perspectiva de gênero na educação, promovendo a discussão sobre as desigualdades e violências, a capacitação contínua dos docentes no enfoque de gênero, a atualização das bases curriculares para que compreendam as demandas sociais e a disponibilização de materiais didáticos sobre o tema (Chile, 2015).

No Brasil, o respeitoà diversidade sexual e o reconhecimento das discriminações de gênero foram temas discutidos nas Conferências Nacionais de Educação - CONAE, ocorridas em 2010 e 2014, bem como incluídos nas Diretrizes Curriculares Nacionais para o Ensino Médio, de 2018, como forma de promoção dos direitos humanos e enfrentamento de todas as formas de discriminação (Reis \& Eggert, 2017: 12-13).

Ocorre que, a implementação de debates institucionais focalizados nas discriminações e preconceitos enfrentados pelas mulheres e, portanto, da necessidade de desenvolvimento de ações embasadas na transversalização ${ }^{6}$ de gênero, ainda enfrenta resistência.

De fato, o questionamento acerca da possibilidade de abordagem dos estudos 7 de gênero no currículo escolar brasileiro evidencia tal posicionamento. Nesse ponto, destaca-se a significativa presença de opositores à discussão acerca das discriminações e opressões sofridas pelas mulheres, bem como resistentes ao fomento de um pensamento crítico que desconstrua os papéis sexuais estereotipados ${ }^{8}$.

Logo, a negação da legitimidade dos debates sobre a opressão social e cultural sofrida pelas mulheres favorece a permanência da cultura patriarcal no contexto atual do país e a naturalização da dominação masculina. Tal fato repercute, também, na desconsideração dos direitos reprodutivos e sexuais das mulheres no panorama legislativo e governamental, pois além da manutenção do controle masculino sobre os corpos femininos, não são criadas leis e políticas públicas que efetivamente considerem a realidade da população feminina e, portanto, contribuam para a consagração de sua autonomia reprodutiva.

Assim, as leis dos demais países latino-americanos analisam o contexto histórico e cultural da sociedade, bem como estudam os padrões comportamentais

6 Conforme definição adotada pela IV Conferência Mundial sobre a Mulher, realizada em 1995, a transversalização de gênero consiste na abordagem das implicações de legislações e políticas públicas adotadas para homens e mulheres, reconhecendo a existência das relações de gênero e avaliando a adequação das ações e programas para a materialização da igualdade entre homens e mulheres (Onu, 1995).

7 Opta-se pela utilização do termo "estudos" em vez de "ideologia”, comumente utilizado, já que o último estigmatiza a reflexão crítica sobre as questões de gênero como um conjunto de ideias voltado à dominação e à manutenção de padrões discriminatórios. Além disso, a expressão "ideologia de gênero" não possui nenhum reconhecimento ou embasamento científico.

8 Nesse posicionamento, inclui-se o atual Presidente da República, que já manifestou sua intenção de censurar o estudo das questões referentes ao gênero nas escolas do país, vide "Bolsonaro: MEC vai elaborar projeto para proibir 'ideologia de gênero' nas escolas” (Amaral, 2019). 
patriarcais e machistas para o estabelecimento de leis e políticas mais efetivas, destinadas não somente à proteção formal dos direitos das mulheres, mas à transformação pragmática do contexto social e à superação das relações de gênero e de poder, fornecendo à população feminina um ambiente mais democrático, apto à manutenção e expansão de seus direitos.

A efetividade das ações dirigidas à tutela das mulheres é dependente, portanto, da incorporação do olhar de gênero. Nesse sentido, a análise das raízes da cultura patriarcal e o reconhecimento da extensão dos padrões discriminatórios são imprescindíveis para a criação de ações focalizadas na perspectiva feminina, uma vez que a neutralidade dos programas governamentais "acaba por reiterar desigualdades de gênero, reafirmando uma posição tutelada e subordinada da mulher tanto no espaço público como no privado" (Farah, 2004: 139).

A recusa em compreender e abordar os processos históricos criados pelos homens para legitimar a subordinação das mulheres e a negação da existência de discriminações de gênero exteriorizam-se, portanto, em leis ineficazes e políticas públicas inócuas, que falham em assegurar os direitos humanos da população feminina brasileira.

Assim, partindo do entendimento que a garantia dos direitos reprodutivos das mulheres pressupõe a constatação da existência de relações de gênero no país e da lógica de dominação do homem sobre a mulher, o fomento de um pensamento crítico sobre os valores internalizados na cultura do país, quanto aos papéis socialmente reservados a cada gênero e os estereótipos de comportamento e subordinação, faz-se necessário, então, para o acolhimento das demandas feministas.

Uma abordagem da perspectiva feminina na elaboração de normas legislativas e políticas públicas é fundamental, portanto, para a consolidação de um espaço democrático que supere as convenções sociais de gênero, no qual seja garantida a visibilidade da mulher e a assegurada a efetiva materialização dos direitos fundamentais, sexuais e reprodutivos, da população feminina.

\section{Conclusão}

A análise da trajetória da luta feminista e do empoderamento das mulheres possibilita a discussão acerca das representações sociais, das desigualdades de gênero e da naturalização dada à dominação da parcela masculina sobre os corpos femininos.

A partir de uma breve observação histórica, demonstrou-se a relevância do movimento feminista na superação de discriminações e violências de gênero, tendo este estimulado transformações econômicas, socioculturais e políticas voltadas à melhoria das condições de vida das mulheres. Diante de um cenário estruturalmente desigual, fundamentado na presença de relações de gênero que legitimam a dominação masculina e, portanto, obstam o empoderamento feminino, analisou-se 
a atuação do movimento diante de tais contextos discriminadores, como os regimes ditatoriais latino-americanos, e sua influência nos avanços referentes à tutela político-legislativa dos direitos das mulheres. Observou-se, assim, que o processo de emancipação sexual das mulheres foi impulsionado pelo movimento feminista, o qual questionou as relações de poder, gênero e a dominação masculina, abrindo espaço para a discussão sobre as discriminações sofridas pelas mulheres e para a contemplação de suas reivindicações.

A abordagem dos estudos de gênero, nesse ponto, destacou-se como efeito do progresso conquistado pelo movimento feminista. A compreensão de tais questões contribuiu, assim, para o reconhecimento das relações de gênero, isto é, dos padrões culturalmente opressores e dos estereótipos de comportamento e, também, para a organização de uma mobilização em favor da desconstrução da cultura patriarcal, que legitima a dominação masculina e obstaculiza a autonomia reprodutiva das mulheres.

Assim sendo, constatou-se que a redemocratização dos países latinoamericanos possibilitou uma nova mirada sobre os direitos das mulheres, sendo ela imprescindível para a incorporação das demandas feministas nas legislações internacionais e brasileiras. A partir disso, foram analisados os principais avanços legislativos referentes à proteção dos direitos reprodutivos das mulheres, bem como as políticas públicas, implementadas nos países em estudo, destinadas à consolidação de tais normas.

Não obstante a construção de um quadro legislativo mais favorável à população feminina, os dados apresentados demonstraram que, no Brasil, o impacto gerado por tais transformações ficou, em diversos contextos, limitado ao âmbito jurídico-normativo, não havendo uma efetiva superação das desigualdades de gênero e uma materialização da autonomia reprodutiva das brasileiras. Evidenciou-se, assim, que o quadro político-legislativo brasileiro traduz-se pela insuficiência dos mecanismos e ferramentas institucionais voltados à ampliação e proteção dos direitos reprodutivos das brasileiras e à coibição de práticas de violência de gênero e sexuais.

Logo, constatou-se que a inefetividade das leis e políticas públicas advém da estruturação social e cultural brasileira, cuja base patriarcal impossibilita a contemplação das mulheres como dignas de direitos iguais aos dos homens garantias individuais pavimentadas pelo princípio jurídico da isonomia constitucional e, portanto, a superação da ideia de que elas estão subordinadas à dominação masculina. Diante disso, verificou-se que as inovações legislativas e governamentais não foram criadas em observância à realidade social enfrentada pelas mulheres, ao caráter sexista das relações sociais e com a finalidade de conferir maior visibilidade às dificuldades enfrentadas pelas mulheres, mas pelo olhar masculino, voltado à preservação de seus privilégios.

Destas constatações, evidenciou-se, outrossim, que o reconhecimento dos direitos das mulheres está vinculado à compreensão das relações de gênero existentes no país, o que faz com que seja necessária uma atuação conjunta do Estado e da 
sociedade para a promoção da igualdade entre os gêneros. A inclusão da perspectiva feminista, tanto no imaginário social quanto na formatação de ações, é imprescindível, assim, para garantir a autonomia reprodutiva das mulheres brasileiras e a efetiva ampliação e asseguração de seus direitos fundamentais.

Dessa forma, o reconhecimento e enfrentamento de uma estrutura social e culturalmente desigual entre os gêneros, marcada pela exclusão das mulheres de certas esferas e pela subjugação destas à dominação masculina é condição para a criação de leis, políticas e ações governamentais que efetivamente levem em consideração a realidade social da população feminina, favoreçam a materialização dos seus direitos reprodutivos e, portanto, contribuam para a superação das estruturas de poder que as mantêm oprimidas.

\section{Referências}

BRASIL. Decreto-Lei no 2.848, de 7 de outubro de 1940. Disponível em: <http://www. planalto.gov.br>. Acesso em: 24 ago. 2019.

BRASIL. Lei no 9.263, de 12 de janeiro de 1996. Disponível em: <http://www.planalto. gov.br m>. Acesso em: 13 out. 2019.

BRASIL. Supremo Tribunal Federal. Arguição de Descumprimento de Preceito Fundamental. Anencefalia. Arguição de Descumprimento de Preceito Fundamental $n$. 54 ajuizada pela Confederação Nacional dos Trabalhadores da Saúde. Relator: Min. Marco Aurélio Mello. Brasília-DF, j.11/o4/2012. Informativo do STF n. 661. Disponível em: <http://www.stf.jus.br>. Acesso em: 24 ago. 2019.

BRASIL. Lei no 13.811, de 12 de março de 2019. Disponível em: <http://www.planalto. gov.br >. Acesso em: 21 jul. 2019.

BRASIL. Comissão Nacional da Verdade. Relatório. Brasília: CNV, 2014.

BRIEGER, Pedro. (2018). El fenómeno de la marea verde en Argentina. CNN Argentina. Disponível em: <https://cnnespanol.cnn.com>. Acesso em: 02 nov. 2019.

BRIOZZO, Leonel; LEÓN, Rodolfo Gómez Ponde de; TOMASSO, Giselle; FAÚNDES, Anibal. The role of medical abortion in the implementation of the law on voluntary termination of pregnancy in Uruguay. International Journal of Gynecology and Obstetrics. Londres (Reino Unido):, v. 134, p. 13-15, 2016.

CARLOTO, Cássia Maria Carloto; DAMIÃO, Nayara André. Direitos reprodutivos, aborto e Serviço Social. Serv. Soc. Soc., São Paulo, n. 132, p. 306-325, ago. 2018. Disponível em: <http://www.scielo.br/scielo>. Acesso em: 13 out. 2019. 
CENTENERA, Mar; MOLINA, Federico Rivas. Senado da Argentina diz 'não' À legalização do aborto e país fica com lei de 1921. El País, Madri (Espanha), 9 ago. 2018. Disponível em: <https://brasil.elpais.com/brasil>. Acesso em: 25 ago. 2019.

CHILE. Câmara de Deputados. Proyecto de Ley no 12038-34, de 21 de agosto de 2018. Disponível em: <https://www.camara.cl>. Acesso em: 02 nov. 2019.

CHILE. Educación para la Igualdad de Género: Plan 2015-2018. Ministério da Educação: Santiago, 2015. Disponível em: <https://www.mineduc.cl>. Acesso em: o3 nov. 2019.

FARAH, Mara Ferreira dos Santos. "Políticas públicas e gênero". In: GODINHO, Tatau; SILVEIRA, Maria Lúcia (Org.). Políticas Públicas e Igualdade de Gênero. São Paulo: Coordenadoria Especial da Mulher, 2004, p. 127-142.

FUNDAÇÃO OSWALDO CRUZ. Nascer no Brasil: inquérito nacional sobre parto e nascimento. Rio de Janeiro: 2014. Disponível em: <http://www6.ensp.fiocruz.br/ nascerbrasil>. Acesso em: 07 set. 2019.

FUNDO DAS NAÇÕES UNIDAS PARA A INFÂNCIA. Escuelas que enseñan ESI: un estúdio sobre Buenas Prácticas pedagógicas en Educación Sexual Integral. UNICEF: 2018. Disponível em: <https://www.unicef.org/argentina>. Acesso em: 03 nov. 2019.

GOMES, Cárita Chagas; DELGADO, Herleide Herculano. Mulheres e transição democrática brasileira (1975-1988): inserção da mulher no espaço público como um passo à democracia. Revista de Teorias da Democracia e Direitos Políticos, Brasília, v. 2, p. 249-270, jan./jun. 2016. Disponível em: <https://indexlaw.org/index.php/ revistateoriasdemocracia>. Acesso em 24 mar. 2019.

JELIN, Elizabeth. Mulheres e direitos humanos. Revista Estudos Feministas, Florianópolis, v. 2, p. 117-149, 1994. Disponível em: <https://periodicos.ufsc.br/index. php/ref/article/view/16293>. Acesso em: 29 mai. 2019.

MONTEIRO, Ester. Lobby do Batom: marco histórico no combate à discriminações. Agência Senado, Brasília, o6 de mar. 2018. Disponível em: <https://www12.senado.leg. br>. Acesso em: 13 jul. 2019.

MONTES, Rocío. Chile avança. El País, Madri (Espanha), 22 ago. 2017. Disponível em: <https://brasil.elpais.com/brasil>. Acesso em: 25 ago. 2019.

MONTES, Rocío. Declaração e Plataforma de Ação da IV Conferência Mundial sobre a Mulher. ONU: 1995. Disponível em: < http://www.onumulheres.org.br>. Acesso em 11 set. 2019 . 
PASSARINHO, Nathalia. Por que Congresso e STF caminham para lados opostos na discussão sobre aborto no Brasil. BBC: Londres (Reino Unido), 14 jun. 2018. Disponível em: < https://www.bbc.com/portuguese/brasil-44458907>. Acesso em: 02 nov. 2019.

PASSARINHO, Nathalia.; FRANCO, Luiza. Com 55\% de gestações não planejadas, Brasil falha na oferta de contracepção eficaz. BBC: Londres (Reino Unido), 26 jun. 2018. Disponível em: < https://www.bbc.com/portuguese/brasil-44549368>. Acesso em: 20 nov. 2019.

PIOVESAN, Flávia. Direitos Humanos e Justiça Internacional: um estudo comparativo dos sistemas regionais europeu, interamericano e africano. 8a edição. São Paulo: Saraiva Educação, 2018.

PITANGUY, Jacqueline. “Movimento de Mulheres e Políticas de Gênero no Brasil”. In: MONTAÑO, Sonia; PITANGUY, Jacqueline.; LOBO, Thereza. As políticas públicas de gênero: um modelo para armar - o caso do Brasil. Santiago (Chile): CEPAL, 2003.

PROGRAMA DAS NAÇÕES UNIDAS PARA O DESENVOLVIMENTO. Indicadores e Índices de Desenvolvimento Humano: Atualização Estatística 2018. PNUD: 2018. Disponível em: < http://www.br.undp.org>. Acesso em: o7 dez. 2018.

REIS, Toni; EGGERT, Edla. Ideologia de gênero: uma falácia construída sobre os planos de educação brasileiros. Educ. Soc., Campinas, v. 39, n. 138, p. 9-26, 2017. Disponível em: < https://www.redalyc.org/pdf/873/87350459002.pdf>. Acesso em: 15 out. 2019.

SCOTT, Joan W. Gênero: uma categoria útil de análise histórica. Revista Educação e Realidade. Porto Alegre, v. 20, n. 2, jul./dez., 1995. Disponível em: <http://www.seer. ufrgs.br>. Acesso em 20 set. 2018.

SILVA, Salete Maria da; WRIGHT, Sonia Jay. As mulheres e o novo constitucionalismo: uma narrativa feminista sobre a experiência brasileira. Revista Brasileira de História do Direito, Belo Horizonte, v. 1, n. 2, p. 170-19o, jul./dez. 2015. Disponível em: <https:// www.researchgate.net/publication>. Acesso em 15 jul. 2019.

SOUZA, Suellen André de. Leis de combate à violência contra a mulher na América Latina: uma breve abordagem histórica. In: Anais do $27^{\mathbf{0}}$ Simpósio Nacional de História, 2013, Natal. Associação Nacional de História, 2013. Disponível em: <http:// www.snh2013.anpuh.org>. Acesso em: 18 jul. 2019.

TELES, Maria Amélia de Almeida. Breve história do feminismo no Brasil. São Paulo: Brasiliense, 1993. 
URUGUAI. Lei no 18.987, de 30 de out. de 2012. Interrupción Voluntaria del Embarazo. Disponível em: <https://legislativo.parlamento.gub.uy>. Acesso em: 25 ago. 2019.

VAIANO, Bruno. "Anticoncepcional” masculinoéadiado por ter reações semelhantes ao feminino. Galileu, Rio de Janeiro, o3 nov. 2016. Disponível em: < https://revistagalileu. globo.com>. Acesso em: 13 out. 2019.

VENTURI, Gustavo; GODINHO, Tatau (Orgs.). Mulheres brasileiras e gênero nos espaços público e privado: uma década de mudanças na opinião pública. São Paulo: Fundação Perseu Abramo; Edições Sesc SP, 2013.

Recebido em 16/12/2019.

Aceito em 24/05/2020. 